\title{
Hormone replacement therapy has no routine role in the management of postmenopausal voiding dysfunction
}

\section{Lesley K. Carr, MD, FRCSC \\ Introduction}

The prevalence of urinary incontinence and storage symptoms are known to increase with age, with rates in postmenopausal women as high as $38 \%{ }^{1,2}$ The bladder trigone, urethra and pelvic floor muscles display estrogen receptors similar to vaginal tissue. ${ }^{3}$ As such, it has long been suspected that decreases in circulating female sex hormones may play an important role in the etiology of lower urinary tract symptoms such as overactive bladder and stress urinary incontinence in postmenopausal women, which are analogous to symptoms seen with postmenopausal vaginal atrophy.

In general, the level of evidence required to recommend an intervention for a specific condition must be balanced with the potential for the intervention to cause adverse effects. In the case of hormone replacement therapy (HRT) in postmenopausal women, it has been well established that there are significant potential adverse effects, including an increased risk of thromboembolic events, ${ }^{4,5}$ cardiac events, ${ }^{4}$ breast cancer ${ }^{5,6}$ endometrial hyperplasia ${ }^{7}$ and endometrial cancer. ${ }^{8}$ Because of these significant risks associated with HRT, the level of evidence required to recommend its use for any condition, including overactive bladder or stress urinary incontinence, must be high. At present, there is no consistent, high-level evidence to support the use of HRT for overactive bladder or stress urinary incontinence.

\section{Basic science studies}

Several studies of estrogen receptors and collagen synthesis support mechanisms whereby HRT may not be beneficial for, or may even be detrimental to, the management of lower urinary tract symptoms in postmenopausal women. In an ovariectomy rat model simulating birth trauma, the estrogen replacement group had higher rates of stress urinary incontinence and reduced bladder capacity compared with placebo. ${ }^{9}$ Significant downregula- tion of urethral $\alpha 1 \mathrm{~A}$ - and $\alpha 1 \mathrm{D}$-adrenergic receptors and upregulation of neuronal nitric oxide synthase were found by immunohistochemical examination in the estrogen-treated group. In another study of 31 women with stress urinary incontinence, prolapse or normal bladder function, women with stress urinary incontinence were found to have lower rates of estrogen receptor staining within connective tissue, muscle and nerve fibres..$^{10}$ The decrease in estrogen receptor presence was felt to be a potential reason for the lack of efficacy of HRT in successfully treating stress urinary incontinence. In addition, estrogen replacement has been shown to have a profound effect on collagen metabolism. ${ }^{11}$ Increased stimulation of collagen degradation via increased matrix metalloproteinase- 2 activity results in significant decreases in total periurethral collagen. ${ }^{11}$ Consequently, damage to paraurethral connective tissue may be a plausible explanation for worsening urethral closure and increased risk of urinary incontinence.

\section{Clinical studies}

Although small studies with short-term followup have suggested a benefit in postmenopausal women with lower urinary tract symptoms from the use of estrogen therapy, ${ }^{12,13}$ larger randomized controlled studies with longer follow-up have found the opposite. ${ }^{14,15}$ The Heart and Estrogen/ progestin Replacement Study collected pre- and postintervention data on lower urinary tract symptoms in women receiving HRT versus placebo. ${ }^{14}$ A total of 1525 of these women reported at least 1 incontinent episode per week and were included for analysis. This group of women had intact uteri and received $0.625 \mathrm{mg}$ of conjugated estrogen plus $2.5 \mathrm{mg}$ of medroxyprogesterone acetate daily, or placebo. By 4 months and persisting to 4 years, the HRT group showed a $70 \%$ and $50 \%$ higher odds of suffering from stress urinary incontinence and urge incontinence, respectively. 
Similarly, a Women's Health Initiative study looked at lower urinary tract symptoms in 23296 women who were randomly assigned to groups that were given $0.625 \mathrm{mg}$ conjugated estrogen (with or without $2.5 \mathrm{mg}$ medroxyprogesterone acetate depending on whether they had had a hysterectomy) or placebo. ${ }^{15}$ Both estrogen alone and estrogen plus progesterone worsened the incidence of stress urinary incontinence and urge incontinence. The Ultra Low Dose Transdermal Estrogen Assessment trial randomly assigned 417 postmenopausal women to groups that were given $0.014 \mathrm{mg} / \mathrm{d}$ transdermal estradiol or placebo with a primary outcome for osteoporosis prevention. ${ }^{16}$ Urinary incontinence data before and 2 years after ultralow-dose unopposed estrogen showed no change in the frequency of incontinence symptoms and no reduction in the risk of developing at least weekly incontinence.

Smaller randomized controlled trials designed specifically to address the question of HRT for urinary incontinence have had comparable results. The Continence Program for Women Research Group randomly assigned 83 postmenopausal women with genuine stress incontinence or detrusor overactivity to 3 months of cyclic conjugated equine estrogens $0.625 \mathrm{mg}$ and medroxyprogesterone $10 \mathrm{mg}$, versus placebo. The group's results found no significant differences in incontinenceepisode frequency, diurnal or nocturnal frequency, or quality of life measures. ${ }^{17}$

Hormone replacement therapy has also been suggested as a management for overactive bladder without urge incontinence. A prospective randomized controlled trial using a $25-\mathrm{mg}$ estradiol- $17 \beta$ implant versus placebo addressed this issue in 40 postmenopausal women. ${ }^{18}$ No benefit was found in the symptoms of wet or dry overactive bladder and a high complication rate was encountered with 9 of the 12 women with uteri experiencing irregular bleeding, 5 of whom went on to undergo hysterectomy. This underscores the concern of unopposed estrogen yielding endometrial hyperplasia.

Several meta-analyses addressing the issue of HRT and incontinence have also been performed. The most current systematic review was performed by Shamliyan and colleagues ${ }^{19}$ whereby they identified 96 randomized controlled trials and 3 systematic reviews published in English between 1990 and May 2007. Their findings suggested that oral hormone administration increased rates of urinary incontinence compared with placebo in most randomized controlled trials, and transdermal or vaginal estrogen resulted in inconsistent improvement of urinary incontinence.

\section{Local vaginal estrogen}

Owing to the many systemic effects of HRT, most urologists would not routinely prescribe these agents. However, it has been suggested that local vaginal estrogen supplementation may be much safer. Three forms are currently widely available in Canada: Premarin cream (conjugated equine estrogens $0.625 \mathrm{mg} / \mathrm{g})$, Vagifem $(25 \mu \mathrm{g}$ estradiol- $17 \beta$ vaginal tablet) or the Estring (7.5 $\mu \mathrm{g}$ estradiol/24 h). Systemic absorption does occur with these agents, however, neither Vagifem nor the Estring used at prescribed doses raise estrogen levels outside of the postmenopausal range. ${ }^{20}$ Thus there would appear to be less concern about adverse effects on the endometrium, breast or heart. However, experts still advise that some stimulation of both breast and endometrium may be encountered and thus women using these agents should have regular mammography and ultrasonography measurements of endometrial thickness every 2 years. ${ }^{21}$

There is reasonable data to suggest that local vaginal estrogen may be more effective than systemic HRT in reducing symptoms of postmenopausal vaginal atrophy (vaginal dryness, pruritis, burning and dyspareunia). ${ }^{22,23}$ Despite this, there is a paucity of data examining the effectiveness of local estrogen preparations to treat lower urinary tract symptoms. Cardozo and colleagues $^{24}$ treated 110 postmenopausal women with Vagifem twice weekly versus placebo for 3 months. At the end of this period, the only urinary symptom that improved was urgency in a subset of women who had a urodynamic diagnosis of sensory urgency.

\section{Other considerations (urinary tract infection)}

Lower urinary tract infections are common in postmenopausal women and may be associated with voiding dysfunction. Both HRT and local vaginal estrogen supplementation have been found in small, randomized studies to reduce the rate of symptomatic infection..$^{25}$ However, a meta-analysis of studies up to 1998 found 10 articles for inclusion 
with only 334 subjects. ${ }^{25}$ Data overall suggested that both systemic and local estrogen reduce the rate of recurrent symptomatic urinary tract infections although some studies have shown no benefit. ${ }^{26,27}$ Overall, the strength of data is not strong enough at present to support widespread use of estrogen in the management of recurrent urinary tract infections.

\section{Conclusion}

The use of systemic HRT in postmenopausal women has been associated with significant, lifethreatening morbidity. The best data to date suggest no benefit for, and possibly a risk of worsening, lower urinary tract symptoms (e.g., overactive bladder, stress urinary incontinence) from the use of HRT. Thus, at present, there is no role for the routine use of HRT to treat overactive bladder or stress urinary incontinence.

It is possible that safer local vaginal estrogen preparations have a different effect on the lower urinary tract compared with systemic HRT. More studies are required to document the effect of these preparations on postmenopausal lower urinary tract symptoms and urinary tract infections.

Assistant Professor, Department of Surgery, University of Toronto, Sunnybrook Health Sciences Centre, Toronto, Ont.

The positions provided in the Point/Counterpoint series are presented as general information and do not necessarily reflect the personal opinions of the authors.

This article has been peer reviewed.

Competing interests: None declared.

\section{References}

1. Diokno $A C$, Brock BM, Brown MB, et al. Prevalence of urinary incontinence and other urological symptoms in the noninstitutionalized elderly. J Urol 1986;136:1022-5.

2. Herschorn S, Gajewski J, Schulz J, et al. A population-based study of urinary symptoms and incontinence: the Canadian Urinary Bladder Survey. BJU Int 2008;101:52-8.

3. losif CS, Batraa SC. EK A, et al. Estrogen receptors in the human female lower urinary tract. Am J Obstet Gynecol Scand 1981;141:817-20.

4. Writing Group for the Women's Health Initiative Investigators. Risks and benefits of estrogen plus progestin in healthy postmenopausal women: principal results from the Women's Health Initiative Randomized Controlled Trial. JAMA 2002;288:321-3.

5. The Women's Health Initiative Steering Committee. Effects of conjugated equine estrogen in postmenopausal women with hysterectomy: the Women's Health Initiative Randomized Controlled Trial. JAMA 2004;291:1701-12.
6. Colditz GA, Hankinson SE, Hunter DJ, et al. The use of estrogens and progestins and the risk of breast cancer in postmenopausal women. N Engl J Med 1995;332:1589-93.

7. Lethaby A, Farquhar C, Sarkis A, et al. Hormone replacement therapy in postmenopausal women: endometrial hyperplasia and irregular bleeding [review]. Cochrane Database Syst Rev 2004:CD000402

8. Ziel HK, Finkle WD. Increased risk of endometrial carcinoma among users of conjugated estrogens. N Engl J Med 1975;293:1167-70.

9. Hayashi N, Bella AJ, Wang G, et al. Effect of extended-term estrogen on voiding in a postpartum ovariectomized rat model. Can Urol Assoc J 2007;1:256-63.

10. Zhu L, Lang J, Feng R, et al. Estrogen receptor in pelvic floor tissues in patients with stress urinary incontinence. Int Urogynecol J Pelvic Floor Dysfunct 2004; 15:340-3.

11. Jackson $S$, James $M$, Abrams P. The effect of oestradiol on vaginal collagen metabolism in postmenopausal women with genuine stress incontinence. BJOG 2002;109:339-44.

12. Walter $\mathrm{S}$, Wolf $\mathrm{H}$, Barlebo $\mathrm{H}$, et al. Urinary incontinence in postmenopausal women treated with estrogens: a double-blind clinical trial. Urol Int 1978;33:135-43.

13. Samsioe G, Jansson I, Mellstrom D, et al. Urinary incontinence in 75-year old women. Effects of oestriol. Acta Obstet Gynecol Scand 1985;93:57.

14. Steinauer JE, Waetien LE, Vittinghoff E, et al. Postmenopausal hormone therapy: Does it cause incontinence? Obstet Gynecol 2005;106:940-5.

15. Hendrix SL, Chochrane BB, Nygaard IE, et al. Effects of estrogen with and without progestin on urinary incontinence. JAMA 2005;293:935-48.

16. Waetien LE, Brown IS, Vittinghoff E, et al. The effect of ultralow-dose transdermal estradiol on urinary incontinence in postmenopausal women. Obstet Gynecol 2005;106: 946-52.

17. Fantl JA, Bump RC, Robinson D, et al. Efficacy of estrogen supplementation in the treatment or urinary incontinence. Obstet Gynecol 1996;88:745-9.

18. Rufford J, Hextall A, Cardozo L, et al. A double-blind placebo-controlled trial on the effects of $25 \mathrm{mg}$ estradiol implants on the urge syndrome in postmenopausal women. Int Urogynecol J Pelvic Floor Dysfunct 2003;14:78-83.

19. Shamliyan TA, Kane RL, Wyman J, et al. Systematic review: randomized, controlled trials of nonsurgical treatments for urinary incontinence in women. Ann Intern Med 2008; 148:459-73.

20. Weisberg E, Ayton R, Darling G, et al. Endometrial and vaginal effects of low-dose estradiol delivered by vaginal ring or vaginal tablet. Climacteric 2005;8:83-92.

21. Cardozo L, Robinson D. Special considerations in premenopausal and postmenopausal women with symptoms of overactive bladder. Urology 2002;60:64-71.

22. Cardozo L, Bachmann G, McClish D, et al. Meta-analysis of estrogen therapy in the management of urogenital atrophy in postmenopausal women: second report of the Hormones and Urogenital Therapy Committee. Obstet Gynecol 1998;92:722-7.

23. Smith $P$, Heimer $G$, Lindskog $M$, et al. Oestradiol-releasing vaginal ring for treatment of postmenopausal urogenital atrophy. Maturitas 1993;16:145-54.

24. Cardozo LD, Wise BG, Benness CJ. Vaginal oestradiol for the treatment of lower urinary tract symptoms in postmenopausal women - a double-blind placebo-controlled study. J Obstet Gynaecol 2001;21:383-5.

25. Cardozo L, Lose $G, M c C l i s h$, et al. A systematic review of estrogens for recurrent urinary tract infections: third report of the hormones and urogenital therapy (HUT) committee. Int Urogynecol J Pelvic Floor Dysfunct 2001;12:15-20.

26. Cardozo L, Benness C, Abbott D. Low dose oestrogen prophylaxis for recurrent urinary tract infections in elderly women. Br J Obstet Gynaecol 1998;105:403-7.

27. Kiaergaard B, Walter S, Knudsen A, et al. Treatment with low dose vaginal estradiol in postmenopausal women. A double blind controlled trial. Ugeskr Laeger 1990; 152:658-9

Correspondence: Dr. Lesley Carr, Department of Surgery, University of Toronto, Sunnybrook Health Sciences Centre, Toronto ON M4N 3M5; Lesley.Car@sunnybrook.ca 